\title{
Atualidades/Actualities
}

\section{O INTERNATO RURAL DO CURSO DE GRADUAÇÃO EM NUTRIÇÃO DA UNIVERSIDADE FEDERAL DE VIÇOSA (BRASIL)*}

\author{
Tânia Ruiz** \\ Percília Dolores Valenza** \\ Marilene Pinheiro Euclydes** \\ Maria do Carmo Fontes de Oliveira** \\ Maria de Lourdes Ferreira Garcia**
}

RUIZ, T, et al. O internato rural do Curso de Graduação em Nutrição da Universidade Federal de Viçosa (Brasil). Rev. Saúde públ., S. Paulo, 19:566-9, 1985.

RESUMO: Com a finalidade de se avaliarem os resultados alcançados numa experiência de internato rural, foram analizados os relatórios dos estudantes que dela participaram. Considera-se internato rural a modalidade de estágio que se caracteriza pela transferência do estudante do "campus" universitário para uma comunidade rural, onde permanecerá por tempo determinado. $O$ internato rural no curso da Universidade Federal de Viçosa distingue-se da estrutura de outras universidades principalmente pela proposta que leva de estimular a comunidade a reconhecer seus problemas. e a organizar-se para solucioná-los. Observou-se ao término desse período que os objetivos traçados não foram satisfatoriamente atingidos. A dificuldade em estimular os habitantes para identificarem os seus próprios problemas e se organizarem no sentido de solucioná-los, a escassez de recursos para manter os estudantes no campo e a descontinuidade do programa foram os entraves fundamentais. Entretanto, constatou-se que, como prática do exercício profissional na área de Saúde Pública e possibilidade de vivenciar o cotidiano de uma comunidade rural, o estágio é de fundamental importância para os estudantes. Concluiu-se tratar-se de uma experiência válida, de acordo com a nova proposta que deverá ser aprimorada para atingir os objetivos iniciais, podendo contribuir como ponto de reflexão para outros cursos de graduação em nutrição do país.

UNITERMOS: Educação em nutrição. Residência e internato.

O internato rural é uma proposta de prática na área de saúde pública, em que estudantes quase-graduados trabalham a nível local de serviços de saúde, supervisionados por técnicos da área.

Levar o estudante a viver a realidade da zona rural, dirigindo a sua formação no sentido de contribuir para a solução da problemática social dos estratos da população mais carentes de serviços, ao lado do objetivo da organização e participação comunitária como metodologia de trabalho, tem sido o alvo perseguido, dentro de um contexto político com metas democráticas.

$\mathrm{Na}$ prática, o internato rural tem-se operacionalizado quase sempre inserindo o estudante ou a equipe multidisciplinar num serviço de assistência básica de saúde. Dessa maneira, sem perder de vista a mobilização da comunidade no sentido da conscientização, priorização e busca das soluções para seus problemas, a equipe presta um serviço assistencial que

\footnotetext{
- Trabalho apresentado no III Seminário de Medicina Social, realizado em Cachoeira do Campo, MG, novembro de 1984.

* Do Departamento de Nutrição da Universidade Federal de Viçosa - Av. P.H. Rolfs, s/n.0 - 36.570 - Viçosa, MG - Brasil.
} 
RUIZ, T. et al. O internato rural do Curso de Graduação em Nutrição da Universidade Federal de Viçosa (Brasil). Rev. Saúde públ., S. Paulo, 19:566-9, 1985.

(dentro de uma concepção popular de que o serviço de saúde atende ao doente) contribui para que a equipe se legitime como tal perante a população.

Com objetivos semelhantes às experiências de outras Instituições nessa área, isto é, a mobilização comunitária como prática de saúde pública e aproximação do estudante de nutrição à realidade rural de países como o nosso, o internato rural foi introduzido no curso de graduação em nutrição da Universidade Federal de Viçosa (UFV) com duas limitações importantes, que foram: em primeiro lugar, ser o curso um dos poucos da área de saúde, na Universidade, o que impediria o trabalho de campo com uma equipe multiprofissional e consequiente inserção do grupo num programa de assistência primária de saúde e, em segundo lugar, o pequeno número de vagas no curso de nutrição, que não possibilitaria continuidade no trabalho desenvolvido, considerando-se também as férias escolares.

O programa de internato rural começou em 1982 e desde então 21 estudantes fizeram o estágio, que é voluntário. $\mathrm{O}$ aluno é enviado a conviver com a comunidade durante sete semanas. Não existe uma programação fixa de atividades a serem desenvolvidas, pois o objetivo central do estágio é o desenvolvimento da comunidade, deixando a priorização de problemas e propostas de solução para serem feitos pelos próprios habitantes. Cada estudante, antes do estágio, lê todos os relatórios que já foram feitos por seus colegas e planeja as suas semanas junto com a população nos primeiros contatos com grupos já formados no lugar, como grupo de jovens, de mães, a escola e outros. O estudante recebe supervisão semanal na comunidade e discute o seu projeto de estágio e o relatório final com os professores da área de nutrição social do Departamento de $\mathrm{Nu}$ trição e Saúde da UFV.
As duas comunidades onde o programa foi implantado refletem o quadro típico da pequena produção no Brasil, isto é, agricultura de subsistência, com minifúndios trabalhados por arrendatários, meeiros e diaristas. Avaliações nutricionais das crianças em idade escolar das duas comunidades mostraram um quadro de desnutrição que, segundo a classificação de Gomez, detecta por volta de $50 \%$ de desnutrição de I grau e $10 \%$ de II grau.

Durante esses três anos de funcionamento do internato rural, tem-se avaliado o programa através dos relatórios dos estudantes, tomando como indicadores as atividades desenvolvidas por eles e problemas da comunidade que foram resolvidos pelo estímulo e participação do estagiário. A curto prazo, não nos parece possível utilizar outros indicadores sem fugir à metodologia de trabalho proposta.

Dessas avaliações, nossas conclusões podem ser resumidas da seguinte maneira.

No que se refere ao desenvolvimento da comunidade: sempre existe por parte desta uma dependência muito grande da presença do estudante ou do técnico extensionista de outras instituições para a realização de reuniões ou programas das atividades. Os habitantes tendem a se isolar do resto do mundo, principalmente por falta de informações, sem elementos para compreender o contexto mais amplo das condições de vida em que se encontram. Ao mesmo tempo, não existe ideologia partidária e sim líderes políticos na comunidade.

Foi feito todo o esforço possível para estimular a organização das comunidades independentemente da presença do estudante, mas não foi verificado resultado, pois já existe uma acomodação aos programas paternalistas. E interessante salientar que nesse aspecto os estagiários nunca são diferenciados pela comunidade dos técnicos de outras instituições, 
RUIZ, T. et al. O internato rural do Curso de Graduação em Nutrição da Universidade Federal de Viçosa (Brasil). Rev. Saúde públ., S. Paulo, 19:566-9, 1985.

apesar de terem objetivos diferentes e explicarem isso à população. A maior necessidade, sempre priorizada pelos habitantes, é o lazer, sendo o alcoolismo o problema social mais importante. Das iniciativas surgidas (olaria, teatro, grupos de costura e outros), a única que tem funcionado ininterruptamente é um parque construido para as crianças, por ter sido uma necessidade sentida, enquanto outras, estimuladas pelo estagiário, como a olaria, por exemplo, só tiveram continuidade durante a permanência dele na comunidade. Um aspecto importante é que a simpatia que o técnico extensionista ou o estudante despertam entre os habitantes acaba sendo um fator essencial de estímulo às reuniōes. Isso pode ser interpretado como uma desconfiança da população ao desconhecido imposto, atitude histórica de defesa, que mostra um inconsciente coletivo que reconhece que o que é oferecido gratuitamente e que vem "mudar as coisaş" tem objetivos e lucros próprios que năo os da comunidade.

Os problemas de desnutrição nunca foram vistos como uma anormalidade $e$ o fenômeno é detectado quando já se traduz como uma doença manifesta ou associada. A grande expectativa que a população tem dos programas está relacionada com a sua parte assistencial, pois a deficiência do sistema de saúde é uma necessidade sentida pela população na premência da evolução dos estados patológicos clinicamente visíveis.

No que se refere ao bom andamento do estágio, a descontinuidade dos programas tem sido um obstáculo em razão dạ férias escolares e também a preferência de alguns estudantes por outros estágios alternativos na área da saúde pública com características assistenciais. Geralmente, optam pelo internato rural os estudantes que durante o curso demonstram sensibilidade aos problemas sociais ou aqueles que durante sua vida acadêmica esti- veram envolvidos em cargos de liderança estudantil. Por outro lado, a experiência também mostra que a opção deve ser espontânea, pois, caso contrário, o que se observa é que ele se sente perdido, sem função e sem identificação com a comunidade, chegando mesmo a se colocar como um estranho no meio.

Acredita-se que a limitação da carga horária em disciplinas da área social e no estágio final de saúde pública sejam também fatores que comprometem tanto a procura quanto o bom desenvolvimento do trabalho pelos estudantes.

Agrava o desestímulo do estudante pelo internato rural a sua preocupação em estar apto a concorrer ao mercado de trabalho, que o espera em breve, e que provavelmente será em outráárea, uma vez que atualmente existem muito poucas oportunidades de trabalho em saúde pública para o nutricionista recém-formado.

Tem sido também um grande entrave ao bom desenvolvimento do internato rural a dificuldade para o financiamento do Programa, tanto em relação aos projetos de pesquisa na área, quanto em relação jà verba que a Universidade destina para a manutenção do aluno no campo.

Cientes dos problemas que dificultam o alcance dos objetivos do internato rural do curso de nutrição da UFV, considera-se que o internato rural, como prática do exercício profissional na área de saúde pública e como possibilidade de vivenciar e compreender o cotidiano de uma comunidade rural, seja de fundamental importância para os estudantes. Trata-se de uma experiência válida que deverá ser aprimorada para atingir os objetivos iniciais, podendo inclusive contribuir como ponto de reflexão para outros cursos de graduação em nutrição do país. Propõe-se, para o curso de Viçosa, um aumento do número de disciplinas da área social no curriculo e aumento da carga horária do estágio de nutrição social. Isso ajudará o futuro nu- 
RUIZ, T. et al. O internato rural do Curso de Graduação em Nutrição da Universidade Federal de Viçosa (Brasil). Rev. Saúde públ., S. Paulo, 19:566-9, 1985.

tricionista a compreender a nutrição como prioridade em saúde pública e a sua causalidade. Propóe-se também iniciar um sistema de vigilância nutricional, nas comunidades, que contribua para destacar essa prioridade.

Finalmente, considera-se de fundamen- tal importância a atuação junto aos órgãos de classe, estimulando a luta por vagas para os nutricionistas sanitaristas nos serviços de saúde pública do país e a defesa junto às instituições competentes de uma política de financiamento para programas e pesquisas na área social.

RUIZ, T. et al. [The rural internship of the graduation course in nutrition of the Federal University of Viçosa (Brazil)]. Rev. Saúde públ., S. Paulo, $19: 566-9,1985$.

ABSTRACT: With the aim of evaluating the results obtained in a new experiment in Internato Rural (rural internship) during its first three years of existence, 22 reports, which had been submitted by 46 student-trainees who participated in this program, were analyzed. Internato Rural involves the transfer of the student from the college campus to a rural community where he stays for a certain period of time. This Internato Rural course program differs from the structure proposed by other universities mainly in that it aims at stimulating the community to identify its problems and to organize itself to solve them. It was observed, at the end of the above mentioned period, that the objectives proposed had not been satisfactorily met. The difficulty in stimulating the community members to identify their own problems and to take the necessary steps to try to solve them was the fundamental obstacle faced. Additional problems were posed by lack of resources to keep the students in the field and program discontinuity, basically due to school vacations and to the limited number of students enrolled in the Internato Rural program, which is elective. It has been realized, however, that as a form of professional practice in the field of Public Health and as an opportunity of experiencing everyday life in a rural community Internato Rural is of fundamental importance for the students. It was concluded that this constitutes a worthwhile experience in accordance with the new proposal which will have to be an improvement so as to meet the initial objectives, and which may also contribute to other graduate programs in nutrition in the country.

UNITERMS: Nutrition, education. Internship and residency.

\section{BIBLIOGRAFIA CONSULTADA}

UNIVERSIDADE FEDERAL DE VIÇOSA Catálogo geral. Viçosa, Imprensa Universitária, 1984. (n. 12).

UNIVERSIDADE FEDERAL DE MINAS GERAIS. Faculdade de Medicina. Departamento de Medicina Preventiva e Social. Internato rural. Belo Horizonte, 1982.
Recebido para publicação em 02/01/1985

Reapresentado em 27/08/1985

Aprovado para publicação em 28/08/1985 